\title{
ANÁLISE DA RESPONSABILIDADE SOCIAL DAS EMPRESAS DE TANGARÁ DA SERRA ATRAVÉS DO BALANÇO SOCIAL
}

\author{
Kátia Regina Endringer ${ }^{1}$ \\ Maykon J. Barbieri Camargo ${ }^{2}$
}

\section{RESUMO}

Há muito se ouve falar em responsabilidade social, porém há pouco este tema vem se tornando comumente conhecido. A RSE (responsabilidade social das empresas) se resume na conduta ética e responsável das empresas para com a sociedade e meio ambiente, o que coloca a entidade empresarial no centro das atenções quando o assunto for o referido, pois a empresa se torna responsável pelo impacto que a sua atividade venha a causar no meio que ela está inserida. Esta pesquisa foi executada a partir da problemática de identificar os aspectos das empresas detentoras do selo balanço social em Tangara da Serra - MT, ainda identificar o interesse por parte das empresas nesse tema e os benefícios oferecidos pelas empresas que divulgam seus balanços sociais, criando um parâmetro para entender através da aplicação de um questionário, o motivo de empresas que atuam no mesmo segmento não publicarem seus balanços. A metodologia adotada foi à exploratória, com pesquisas documentais em artigos e sites da área e ainda aplicação de questionário. Ao final da pesquisa constatou-se que as empresas que publicam seus balanços em Tangará da Serra são caracterizadas pelo domínio do mercado nos seus segmentos e estão preocupadas em manter uma imagem socialmente responsável perante seu público, ainda constatou-se que em modo geral as empresas são conscientes sobre a necessidade de voltar suas atenções ao meio ambiente, porém apenas algumas já dispõem de projetos para fazê-lo.

Palavras chave: RSE, Certificado de responsabilidade, Stakeholders.

\section{INTRODUÇÃO}

O termo Responsabilidade social, apesar de estar ganhando espaço e se tornando mais comum não é nada atual, no Brasil desde os anos 60 já existem discussões e ações em prol deste assunto, conforme afirma Ashley, Coutinho e Tomei (2000) a responsabilidade social das empresas é um assunto que vem fazendo parte das discussões acerca do caráter empresarial das organizações e torna-se cada vez mais popular, tendo em vista a divulgação na mídia dos feitos e comprometimento das entidades com o meio em que está inserida.

A partir do conhecimento das pessoas da existência de organizações que trabalham não só voltadas para o enriquecimento próprio, mas também para o bem estar social e preservação ambiental, nasce uma cobrança e maior observância por parte das pessoas em geral para com as empresas que ainda não se adaptaram a nova concepção de entidade geradora de recursos.

\footnotetext{
${ }^{1}$ Acadêmica do Curso de Ciências da UNEMAT $\neg$ Campus de Tangará da Serra, katiaendringer@ hotmail.com ${ }^{2}$ Professor do curso de Administração da UNEMAT - Campus de Tangará da Serra, maykon_adm@ @hotmail.com Volume 1, Número 2 Revista UNEMAT de Contabilidade Jul./dez. 2012 UNEMAT
} 
Para Baldo (2002) a responsabilidade social de uma entidade se resume na sua opção por participar mais ativamente das ações comunitárias do meio em que está inserida e minimizar possíveis danos ambientais conseqüentes do tipo de atividade que desempenha. Conforme Santolin e Frey (2005) responsabilidade social nada mais é que um exercício permanente de deveres, no intuito de garantir aos cidadãos os direitos mais básicos: educação, saúde, habitação, cultura, lazer e segurança.

Para tornar públicas as ações realizadas, as empresas se utilizam de uma ferramenta que funciona como um instrumento de gestão e de informações, o Balanço Social, que visa evidenciar, da forma mais transparente possível, informações econômicas e sociais, do desempenho das entidades, aos diferenciados usuários, entre estes os funcionários. (TINOCO, 2001 p.14)

O marketing feito pelas empresas que desenvolvem projetos sociais ou que despendem recursos direcionados às causas sociais ocasiona a valorização da marca dessa entidade através do surgimento de certa simpatia por parte dos consumidores (VEIGA-NETO; PANHOSSI; GODOY 2004).

Partindo dessa premissa o intuito desse artigo é analisar e evidenciar o real objetivo dessas organizações que usam o balanço, comparando com as empresas de mesmo segmento, que não publicam.

\footnotetext{
A divulgação da marca, produto e imagem da empresa deve ser uma conseqüência do marketing social, não o fator de evidência. Existe sim um marketing social ético, firme e responsável, que se contrapõe ao marketing de causa (marketing comercial), que é oportunista, difamador e de curta visão. Esse marketing é adotado pelas empresas como plataformas de seus negócios, destinando parte das suas vendas para atrair público e aumentar a venda de seus produtos. (VEIGA-NTO; PANHOSSI; GODOY, 2004, p.7)
}

Para Baldo (2002), as empresas que cumprem seu papel social, acabam por atrair mais consumidores e em contra partida ela está investindo na sociedade conseqüentemente no seu próprio futuro, estas, portanto detêm o direito, antes do dever, de dar publicidade às suas ações.

No Mato Grosso a criação da Lei da Responsabilidade Social no dia 25 de junho de 2002 foi o primeiro passo de uma trajetória marcada por avanços do conceito de comportamento socialmente responsável, segundo dados disponibilizados no site da Assembléia Legislativa de MT (2012), a quantidade de empresas que adquirem a certificação através da publicação dos seus balanços tem aumentado a cada ano sendo que no ano de 2006 
Análise da responsabilidade social das empresas de Tangará da Serra através do Balanço Social

Kátia Regina Endringer

Maykon J. Barbieri Camargo

foram apresentados para publicação 5 balanços e em 2011, 39 balanços foram publicados o que representa $78 \%$ de aumento, isso demonstra uma mudança de mentalidade e comportamento relativos à gestão das empresas mato-grossenses.

O presente artigo discorre sobre a Responsabilidade Social das Empresas de Tangará da Serra, detentoras do selo Balanço Social, através dos indicadores contidos nos balanços publicados. Ainda identificar se as empresas que atuam no mesmo segmento têm conhecimento sobre a existência do Selo Balanço social e Mato Grosso.

Este trabalho tem como objetivo geral identificar o interesse por parte das empresas nesse tema, ainda constatar os benefícios oferecidos pelas empresas que divulgam seus balanços sociais, criando um parâmetro para entender através da aplicação de um questionário, o motivo de empresas que atuam no mesmo segmento não publicarem seus balanços. Como objetivos específicos: identificar e analisar os benefícios oferecidos à sociedade e ao ambiente interno, pelas entidades que publicam seus balanços sociais e apontar o motivo da não elaboração do balanço social por parte das empresas do mesmo segmento e porte.

Sabendo-se da atual importância das organizações desempenharem ações sociais e divulgarem para a comunidade, levantou-se a problemática de identificar quais são os aspectos das organizações detentoras do Selo Responsabilidade Social?

\section{REFERENCIAL TEÓRICO}

\subsection{Responsabilidade Social}

O termo responsabilidade social não é recente, através de estudos bibliográficos podese afirmar que, desde os anos 50, nos Estados Unidos e na Europa, já se verificava uma mutação nos valores da conjuntura socioeconômica, gerando reivindicações generalizadas por parte da sociedade em relação ao contexto socioambiental das empresas e sua forma de atuação (OLIVEIRA, 2010).

Responsabilidade social é a capacidade de a empresa colaborar com a sociedade, considerando seus valores, normas e expectativas para o alcance de seus objetivos. No entanto, o simples cumprimento das obrigações legais, previamente comportamento socialmente responsável, mas como obrigação contratual óbvia. (OLIVEIRA, 1984, p.205).

Esse tema pode ser interpretado de várias formas, para Santolin e Frey (2005) a responsabilidade social está relacionada a diferentes ideias, para alguns consiste na 
Análise da responsabilidade social das empresas de Tangará da Serra através do Balanço Social

Kátia Regina Endringer

Maykon J. Barbieri Camargo

responsabilidade legal das organizações enquanto para outros o comportamento social responsável das empresas está mais ligado ao sentido ético da questão. Sendo assim pode-se entender que existem vários tipos de interpretação para o tema e segundo Ursini e Sekiguchi e (2005) que fazem parte dos formadores de opinião que seguem a segunda linha de raciocínio conforme descrito acima, estes afirmam que responsabilidade social é quando a empresa utiliza-se de um comportamento responsável, transparente e ético para lidar com sua cadeia de relações, cadeia esta composta por pessoas que possuem seus valores e identidades.

Para Amoroso (2003) o desenvolvimento de uma nação não está somente relacionado às mudanças e avanços na área econômica, mas de um reequilíbrio dos desafios sociais e de distribuição de renda ocasionados por este próprio crescimento. Segundo o autor, a responsabilidade social se resume nas benfeitorias proporcionadas pelas organizações para as pessoas e meio ambiente, se não na sua totalidade pelo menos nos arredores de onde esta se encontra instalada. Deve-se ressaltar que se dedicando a este meio a empresa conquista a simpatia dos seus consumidores e de quebra a preferência dos mesmos.

\subsection{Responsabilidade Social das Empresas Evolução Histórica}

Partindo do tema responsabilidade social chega-se a responsabilidade social das empresas RSE, que significa a tomada de uma conduta ética e responsável por parte da entidade.

RSE é o compromisso empresarial de contribuir para o desenvolvimento econômico sustentável, trabalhando em conjunto com os empregados, suas famílias, a comunidade local e a sociedade em geral para melhorar sua qualidade de vida, de maneira que sejam boas tanto para as empresas como para o desenvolvimento. (BANCO MUNDIAL, 2002. apud, SANTOLIN; FREY 2005, p.3.)

Para Kreitlon (2004) a preocupação com a ética e com a RSE está firmemente inscrita na gama de debates contemporânea, no mundo dos negócios, e das grandes corporações transnacionais particularmente, as discussões e iniciativas relativas ao tema já chegaram mesmo a se tornarem comuns. Para o autor, este tema está cada vez mais fazendo parte do cotidiano das pessoas e tem tomado espaço na pauta de decisões empresariais, tendo em vista a relevância do assunto para a definição do "caráter" empresarial.

Segundo uma definição mais atual do instituto Ethos (2011), RSE é a forma de gestão embasada no comportamento ético e transparente da empresa para com seus públicos, buscando a preservação do meio ambiente e cultura para gerações futuras. A partir dessa definição pode-se entender o motivo da atual preocupação acerca desse tema, pois a atenção 
Análise da responsabilidade social das empresas de Tangará da Serra através do Balanço Social

Kátia Regina Endringer

Maykon J. Barbieri Camargo

dedicada ao meio ambiente, cultura e respeito pela sociedade fazem parte de uma gestão digna e respeitada.

O termo responsabilidade social da empresa foi salientado, pela primeira vez, nos Estados Unidos da América, quando a guerra do Vietnã, durante o governo de Nixon, gerou profundo descontentamento popular, fazendo com que a sociedade manifestasse e reprovasse tal litígio (NEGRA; TEIXEIRA; CARMO 2001). De acordo com Martins, Bernardo, Madeira (2002), na Europa especialmente na França, Alemanha e Inglaterra, foi no inicio da década de 70, que a sociedade começou a cobrança por maior responsabilidade social das empresas. (INSTITUTO ETHOS, 2011).

Frey e Filho (2003) salientam que nos últimos 20 anos, teóricos de diversas nacionalidades e ideologias estão procurando incitar as empresas para uma administração mais humanitária, não se baseando apenas na geração de lucro, mas também no conceito do trabalho integral do homem. Ainda segundo Frey e Filho (2003) é a partir desse conceito de mudança social que se chega à responsabilidade social, atualmente fundamental para a continuidade das empresas em longo prazo. Conforme afirmação dos autores a relevância do tema se dá a partir das cobranças que a sociedade de modo geral vem aplicando nas empresas.

No Brasil, os primeiros indícios de mudança de mentalidade empresarial já podem ser notados desde meados da década de 60 (SILVA; FREIRE 2001) quando um movimento nascido em 1961 por alguns empresários que fundaram a Associação de Dirigentes Cristãos de Empresa de São Paulo - ADCE-SP. Com o crescimento da Associação para outros estados nasceu à necessidade de se criar uma direção para atender a demanda nacional. Daí o surgimento da Associação de Dirigentes Cristãos de Empresa do Brasil, criada em 1977. Desde esse período a ADCE vem tomando frente nos assuntos sobre as funções sociais das empresas. (MARTINS; BERNARDO; MADEIRA, 2002)

\begin{abstract}
A ADCE é uma sociedade civil de caráter cultural e educativo, sem fins lucrativos, com sedes e foro na cidade onde funciona. Tem por objetivo, estudar, viver e definir nas atividades econômica e social os princípios e aplicações dos ensinamentos cristãos, através da educação e da formação do meio empresarial. Para isto, promovem estudos, pesquisas, cursos, conferências, seminários, congressos, publicações e quaisquer atividades que possam contribuir para o atendimento pleno das metas adeceanas (ADCE-SP, 2011)
\end{abstract}

Tinoco (2001) defende um conceito modernamente aceito, diz que a existência das entidades não pode justificar-se unicamente pela capacidade que elas possuam de gerar lucros 
a seus proprietários. Com base nessa afirmação, pode-se esperar que os valores das empresas estejam também relacionados aos seus ideais, missão, visão e valores. Já Baldo (2002) entende que é através da sociedade que a entidade empresarial se estabiliza e usufrui dos recursos naturais existentes, que constituem o patrimônio natural desta sociedade e utiliza os recursos de capital, tecnológicos e de mão-de-obra, que integram seu patrimônio cultural, social e econômico.

Seguindo a linha de raciocínio dos autores acima, pode-se ter o entendimento que a valoração do ponto de vista social de uma empresa não ocorre apenas acerca da sua liquidez financeira e econômica ou dos benefícios que esta pode trazer para a sociedade como entidade geradora de riquezas, mas também pelo empenho desta na responsabilidade com o meio na qual está inserida e sua atenção voltada para as causas sociais.

\footnotetext{
Atualmente, vivemos um momento histórico, representado pelo novo governo de fortes bases sociais e uma articulação singular da sociedade civil. Afinal, não existe política social que vigore sem um movimento engajado da sociedade. O cidadão consciente consegue questionar direitos ao governo. (AMOROSO, 2003, p.2)
}

Conforme ressalta o autor, o surgimento dessa nova mentalidade não se limita apenas ao simples interesse do governo e das organizações em proporcionar melhores condições de vida às pessoas e mais respeito ao meio ambiente, e sim na cobrança por parte da sociedade por um comportamento mais consciente das empresas e um maior respaldo por parte dos governos.

As empresas, públicas ou privadas, querendo ou não, são impulsionadoras no processo de desenvolvimento (BALDO, 2002). Levando em consideração que desenvolvimento não significa apenas crescimento econômico, mas também evolução social pode-se chegar à conclusão de que ao consumir e usufruir dos recursos disponíveis na sociedade a empresa passa a ter uma divida social com este meio e a partir de projetos voltados para o bem estar das pessoas envolvidas nesse processo de alavancagem da entidade, sejam como colaboradores ou consumidores, a empresa devolve um pouco do que usurpou da sociedade.

\subsection{Responsabilidade Social das Empresas e seus Stakholders}

Para Oliveira (1984) os interessados pela responsabilidade social praticada pelas empresas podem ser vários, consumidores, colaboradores, acionistas, comunidade dentre outros e na pesquisa realizada por ele os empregados ficaram em último lugar no ranking de importância dedicada por estas ações, sendo que em primeiro lugar ficaram acionistas e a 
Análise da responsabilidade social das empresas de Tangará da Serra através do Balanço Social

comunidade. Mas para Oliveira esse resultado pode variar de acordo com o porte da empresa e características da região analisada.

Esses beneficiários ou pessoas na qual os benefícios proporcionados pelas organizações afetam, seja de forma direta ou indireta são conhecidos como stakholders (BAGGENSTOSS, 2009). Para Quelhas, Filho e Meiriño (2007) apud, Baggentoss (2009) stakeholders é um termo em inglês muito usado para definir (partes interessadas, envolvidas), ou seja, todas as pessoas a quem a empresa possa atingir por meio de suas opiniões ou ações.

Frey e Filho (2003) acreditam que essa dedicação por parte da empresa, entendida como responsabilidade social vai além de colaborar com filantropia ou ajudar pessoas menos favorecidas e sim na forma com que a empresa age em relação aos seus colaboradores, meio ambiente e todas as pessoas relacionadas à continuidade desta. Logo, pode-se afirmar que o que se deve levar em consideração é, até que ponto ser socialmente responsável influencia nas tomadas de decisão de uma empresa e não apenas se voltar para ações beneficentes esporádicas que venham a ser praticadas por esta.

Para Varella, Costa e Dolabella (1999) com as recentes mudanças socioambientais, as entidades estão deixando de visar apenas os próprios interesses para dar também atenção aos anseios das pessoas relacionadas à sua existência, a partir daí acontece uma nova discussão acerca das reais responsabilidades das empresas.

\subsection{O Estado Enquanto Provedor Social.}

Partindo da deficiência do Estado em suprir as grandes demandas sociais, empresas dos mais diversos ramos econômicos atuam cada vez mais de forma interessada em incorporar um discurso social mais justo, segundo Neto Melo e Froes (2002) e Veiga-Neto, Panhosi e Godoy (2004) esta nova ordem social surgiu a partir da falência do Estado, principal provedor social.

O público, as empresas privadas e a população, a favor das causas sociais, essa simples definição representa um dos mais contemporâneos conceitos econômicos estabelecidos no Brasil nos últimos tempos: o Terceiro Setor (BALDO, 2002). Ainda para Baldo (2002) e Neto, Melo e Froes (2002) a definição de Terceiro Setor surgiu já na primeira metade do século XX, nos Estados Unidos, o que seria a mistura dos dois clássicos setores econômicos da sociedade: setor público, representado pelo estado e o setor privado, representado pelas entidades empresariais em geral. 
Com o surgimento de novos conceitos sobre entidades geradoras de recursos sejam elas públicas, privadas ou filantrópicas, novas discussões acerca das atividades desempenhadas por estas também foram lançadas, a filantropia é diferente de responsabilidade social simplesmente porque filantropia é uma ação social, seja praticada isoladamente ou sistematicamente, e nada diz sobre a visão da empresa e sobre a estratégia na sua gestão e na sua atuação social. (MAIA, 2002. Apud, SANTOS, 2003).

\footnotetext{
Responsabilidade social não é sinônimo de filantropia, mas representa a sua evolução ao longo do tempo. Enquanto a filantropia trata das ações de benemerência da empresa por meio de participações em campanhas isoladas ou doações aleatórias que faz a instituições sociais, o conceito de responsabilidade social possui uma amplitude muito maior. (SANTOS, 2003)
}

Com base nas afirmações dos autores acima, responsabilidade social envolve toda uma política empresarial, visão, missão e valores de uma entidade, por isso não deve ser confundida com filantropia que consiste em uma ação social apenas.

Apesar da política de boa conduta adotada por parte das empresas e cobrada pela mídia e comunidade, o questionamento acerca dos reais motivos que levam uma entidade a tomar a decisão de aderir à nova concepção de empresa confiável e respeitada. Segundo Friedman (1970) apud, Santolin e Frey (2005), a responsabilidade social das empresas nada mais é que o interesse no aumento do próprio lucro e que todo o discurso debatido acerca dessa "responsabilidade" não passa de tolice.

\subsection{Balanço Social e sua Evolução Histórica}

Partindo do pressuposto que a existência de uma preocupação com o social vem somar na boa imagem da entidade e que existe a necessidade mostrar resultados, chegamos então à outra necessidade que é a de uma ferramenta que evidencialize com objetividade e clareza o volume monetário despendido pela empresa para as causas sociais.

Em nível mundial "o primeiro balanço social foi realizado na França, pela empresa Singer, em 1972, e, em 1977, naquele mesmo país, foi aprovada a Lei o tornava obrigatório para as empresas com mais de setecentos empregados". (VIEIRA, 2006, p.37 apud, QUINTANA, et al. 2007).

No Brasil a primeira campanha para incentivar a publicação do balanço social aconteceu em 1997 pelo Instituto Brasileiro de Análises Social e Econômico o IBASE (INSTITUTO ETHOS, 2011). O Ibase é uma organização da sociedade civil fundada em 
Análise da responsabilidade social das empresas de Tangará da Serra através do Balanço Social

Kátia Regina Endringer

Maykon J. Barbieri Camargo

1981 por, entre outros, o sociólogo Herbert de Souza, o Betinho e tem como objetivo "a radicalização da democracia e a afirmação de uma cidadania ativa”. (IBASE, 2011).

Balanço social é um instrumento de gestão e de informações que visa evidenciar, da forma mais transparente possível, informações econômicas e sociais, do desempenho das entidades, aos diferenciados usuários, entre estes os funcionários (TINOCO, 2001 p.14). O balanço social demonstra uma serie de informações relativas à ecologia, pessoas inseridas nas atividades desenvolvidas por esta entidade, estejam elas sendo afetadas direta ou indiretamente, como exemplo: cônjuge e dependentes de funcionários e também os esforços realizados pela empresa para a conservação do meio ambiente.

Frey e Filho (2003) têm o entendimento de que o balanço social enquanto estratégia de mudança de impacto sociocultural tem a finalidade de fornecer ao seu universo de usuários, informações confiáveis para que estes possam fazer uma avaliação sobre a qualidade dos investimentos e a aplicação de recursos feita pelas empresas.

Conforme Santolin e Frey (2005) ao final da pesquisa realizada por eles sobre "o papel do balanço social na gestão empresarial" a atual situação dos balanços sociais publicados, com notas explicativas de baixa qualidade, sem padronização e poucas explicações sobre os aspectos negativos da atividade empresarial desempenhada pela entidade remete a um pensamento acerca da necessidade de melhorias.

Ainda segundo Santolin e Frey (2005) a globalização e a abertura cada vez maior dos mercados estão introduzindo mudanças no comportamento das empresas e que embora ainda não seja obrigatória a publicação do balanço social, cada vez mais é fixado como um instrumento na administração das empresas.

\subsection{Responsabilidade social no Estado do Mato Grosso.}

O estado do Mato Grosso é o segundo estado brasileiro a instituir a lei da Responsabilidade Social, ficando atrás do estado do Rio Grande do Sul que foi o estado pioneiro no Brasil (BAGGENSTOSS, 2009). No dia 25 de junho de 2002 foi instituída a Lei 7687/02 que assim como é denominada cria o Certificado de Responsabilidade Social no Estado do Mato Grosso e dá outras providencias, esta Lei criada pelos deputados Humberto Bosaipo, Riva e Eliene e sancionada pelo então governador José Rogério Sales, em seu $1^{\circ}$ artigo discorre que. 
"Fica instituído o Certificado de Responsabilidade Social - MT a ser conferido, anualmente pela Assembléia Legislativa do Estado de Mato Grosso, às empresas, órgãos públicos e demais entidades com sede no Mato Grosso que apresentarem seu Balanço Social do exercício anterior”. (ASSEMBLEIA LEGISLATIVA DE MATO GROSSO 2010)

Em 2007 a (ALMT) Assembléia Legislativa de Mato Grosso criou a comissão mista, responsável pela organização e coordenação do processo de certificação das empresas participantes. A comissão mista ainda detém a responsabilidade pela cassação desse certificado, no caso de a empresa contemplada sofrer alguma denuncia por desrespeito de leis ambientais, trabalhistas, sociais ou previdenciária esta poderá vir a perder seu certificado (BAGGENSTOSS 2009).

Para o desenvolvimento desse trabalho a ALMT criou através do ato $\mathrm{N}^{\circ}$ 07/07, em 02/04/2007, a Comissão Mista de Responsabilidade Social do Estado de Mato Grosso, que trata o Artigo $4^{\circ}$ da Lei $\mathrm{n}^{\circ} .8 .477$ - D.O. 15.05.2006, responsável pelo estabelecimento do regulamento (edital) para concessão do certificado de Responsabilidade Social, aplicáveis aos Balanços Sociais. (ASSEMBLEIA LEGISLATIVA DE MATO GROSSO 2010)

Conforme disponibilizado em seu endereço eletrônico, em 2006 no dia 11 de dezembro a Comissão Mista e a Assembléia Legislativa, certificaram 05 empresas estabelecidas no Estado. Em 2007 foram certificadas 18 empresas com o "Certificado de Responsabilidade Social de Mato Grosso", sendo que destas 2 empresas eram tangaraenses. No ano de 2008 foram certificadas 24 empresas, neste ano o número de empresas de Tangará da Serra diminui para 1, em 2009 foram 34 empresas, sendo 2 de Tangará e em 2010 foram enviados 38, balanços sociais para análise sendo que 37 deles foram aprovados, neste ano a quantidade de empresas tangaraenses aumentou significativamente subindo para 6.

Com base nas afirmações acima, pode-se ter o entendimento que cada vez mais as empresas estão aderindo à idéia de se tornar publicamente responsáveis. "Empresas que conseguem o Selo de Responsabilidade Social devido às ações adotadas em prol do econômico, social e ambiental tem mais credibilidade entre os consumidores/clientes, ganhos em produtividades e imagem consolidada no mercado". Afirmação do gerente executivo de Responsabilidade Social do SESI Nacional Alex Mansur, em uma palestra ministrada no V Seminário de RS de MT realizada na Assembléia Legislativa.

\section{METODOLOGIA}

Para desenvolver o tema proposto foi realizada uma pesquisa exploratória, que possui como característica concentrar-se em algo que necessita ser esclarecido ou explorado nesse campo de conhecimento. (RAUPP; BEUREN, 2006). A pesquisa foi realizada a no mês de 
março do ano de 2012 e concluída em abril de 2012 e teve seu espaço delimitado às empresas que divulgam e as demais do mesmo setor que não divulgam seus balanços sociais em Tangará da Serra - MT.

A fim de adquirir informação sobre quais benefícios tais empresas proporcionam aos seus stakeholders, foram analisados os balanços sociais das seguintes empresas: Agro Amazônia Produtos Agropecuários Ltda, Unimed Vale do Sepotuba, Medicina Diagnóstica Doyon, Inviolável Tangará Ltda, Minerva Serviços de Contabilidade e Inasb Planos Odontológicos que têm seus balanços publicados no site da Assembléia Legislativa de Mato Grosso como detentoras do selo Responsabilidade Social no ano de 2010.

$\mathrm{O}$ procedimento adotado para conduzir essa pesquisa foi o da pesquisa documental e bibliográfica buscando o levantamento de dados através de uma análise de documentos, livros e artigos. Para Raupp e Beuren (2006) a pesquisa documental pode ser confundida com a bibliográfica, porém ressalta que as duas se diferem pela característica de que a bibliográfica se utiliza da contribuição de vários autores enquanto a documental faz o uso de materiais que ainda não receberam tratamento analítico e que podem ser reformulados de acordo com o objetivo da pesquisa sendo esses documentos os balanços sociais do ano de 2010 e dados fornecidos por sites da área, quanto às bibliografias serão utilizados livros e artigos sobre o assunto.

Tendo em vista o interesse do trabalho em fazer comparativo entre empresas que publicam seus balanços e empresas que não publicam, foi também aplicado questionário com perguntas objetivas e descritivas a todas às empresas do mesmo segmento, sendo 34 escritórios de contabilidade, 1 empresa do ramo de plano de saúde, 4 empresas de máquinas agrícolas e 2 de segurança patrimonial, no objetivo de obter o entendimento do motivo pela qual essas empresas não divulgam seus balanços.

A pesquisa de campo segundo Fuzzi (2010) consiste na coleta de dados referentes ao fenômeno que será estudado e é a partir da análise e interpretação desses dados que se chega à explicação e compreensão do problema pesquisado. Ainda segundo Fuzzi (2010) uma pesquisa exige determinação de técnica de coleta de dados e que dependendo dessas técnicas a pesquisa de campo poderá ser caracterizada como qualitativa ou quantitativa.

Quanto à abordagem da pesquisa, esta aconteceu acerca dos dois acima propostos, nos âmbitos, qualitativo e quantitativo, para Sampieri (2006) a pesquisa qualitativa ocorre acerca 
Análise da responsabilidade social das empresas de Tangará da Serra através do Balanço Social

de levantar dados de disposição numérica enquanto a qualitativa busca analisar dados a partir de descrições e observações. Para Oliveira et al. (2003) "na abordagem quantitativa, descrevem-se as técnicas estatísticas. Na abordagem qualitativa, mostra-se o referencial teórico que orienta a análise".

Foi utilizada como uma das principais fontes de pesquisa para a elaboração deste artigo a dissertação de Salli Baggenstoss, apresentada como pré-requisito para obtenção de título de Mestre em Engenharia de Produção da Universidade Federal de São Carlos. Nesta pesquisa a autora realizou um estudo sobre o Certificado de Responsabilidade Social de Mato Grosso no intuito de conhecer o processo de legitimação da responsabilidade social no estado do Mato Grosso. A pesquisa de Baggenstoss aconteceu acerca do objetivo de atestar a credibilidade da Lei de Responsabilidade Social de MT e da Comissão Mista criada para avaliar os balanços enviados pelas empresas para avaliação.

Sendo assim a presente pesquisa ocorreu visando identificar os aspectos das empresas detentoras do Certificado de Responsabilidade Social na cidade de Tangará da Serra, através da analise dos balanços sociais e aplicação de questionário.

\section{RESULTADOS}

\subsection{Dos balanços analisados}

Foram analisados os balanços sociais de seis empresas situadas na cidade de Tangará da Serra conforme proposto. Ainda foi aplicado um questionário composto de 24 questões fechadas, nessas e em mais 41 empresas que atuam no mesmo segmento contabilizando um total de 47 questionários aplicados, sendo que uma empresa, do ramo de máquinas agrícolas se recusou a responder logo a pesquisa foi realizada com os dados dos questionários de 46 empresas. A proposta da análise dos balanços foi de identificar os benefícios oferecidos por essas empresas e com a finalidade de compreender o motivo da não confecção do balanço social pelas empresas concorrentes, se por motivo de não julgar o enfoque no social importante para a imagem da empresa ou simplesmente não conhecer o balanço e desconhecer seus benefícios.

\subsection{Projetos desenvolvidos pelas empresas que publicam seus balanços.}

Das seis empresas que publicam seus balanços, cinco delas desenvolvem projetos para o ambiente externo e apenas uma investe em benefícios somente para o público interno. Quatro dessas cinco empresas desenvolvem em conjunto um projeto voltado para o meio 
externo, o Projeto Flauta Mágica. São elas: Data Med, Inasb, Minerva e Inviolável. Esse projeto assiste 30 crianças que residem no bairro Jardim dos Ipês, propiciando a elas aulas de flauta doce e lanche para todas as crianças em todas as aulas. O valor do salário do professor é custeado pelas empresas parceiras neste projeto.

A Unimed Vale do Sepotuba através do Instituto Pró Vale realiza vários projetos voltados para a sociedade, colaboradores da empresa e meio ambiente, são eles: Doutores do riso, 3R's, Capoeira cidadã, Judô Cidadão, Projeto Integração, Caminhada de combate a Hipertensão, Flauta Cidadã e $1^{\circ}$ passo - Manicure \& Pedicure.

- O projeto Doutores do riso é desenvolvido com a colaboração de voluntários que se caracterizam de palhaços e visitam hospitais da rede pública e privada na cidade a fim de levar alegria e descontração às crianças que estão hospitalizadas, esta ação visa ajudá-las a esquecer o sofrimento e a dor que a enfermidade os causa, auxiliando-as na aceitação do tratamento, contribuindo assim para a recuperação das mesmas, por mês em torno de 50 crianças são atendidas pelo projeto doutores do riso.

- O projeto 3R's visa conscientizar as pessoas sobre a utilização adequada dos meios de consumo, reforçando a necessidade da contribuição das pessoas com a coleta seletiva, REDUZIR, REUTILIZAR E RECICLAR assim como é chamado; este projeto é realizado em parceria com a prefeitura municipal de Tangara da Serra, Escolas Ideal, Ipes e Unemat, e tem como objetivo aproveitar e reduzir o lixo urbano, neste sentido aproximadamente 1.500 pessoas já participaram de palestras educacionais e de conscientização sobre a necessidade e urgência da separação adequada do lixo.

- O projeto Capoeira Cidadã é desenvolvido em parceira com a Associação Fonte de Luz, oferecendo aulas de capoeira para 60 crianças carentes que residem nos bairros Jardim dos Ipês e Vila Nazaré, este projeto visa ocasionar a inserção social e educacional dessas crianças, ainda despertar o interesse dessas crianças pelo esporte e os distanciar da violência. As crianças que participam desse projeto ainda têm o acompanhamento de uma psicopedagoga que confecciona semestralmente um relatório sobre o desenvolvimento alcançado pelas mesmas.

- O projeto Judô cidadão é realizado em parceria com a associação Fonte de Luz e associação Estrela da Serra e atende 60 crianças, as aulas de judô são ministradas em horário que essas crianças não estão na escola e tem o objetivo de estimular o esporte saudável e 
Análise da responsabilidade social das empresas de Tangará da Serra através do Balanço Social

Kátia Regina Endringer

Maykon J. Barbieri Camargo

educá-las para a convivência em sociedade, ensinando-as através do esporte a praticar o respeito ao próximo e agregando valor em suas personalidades.

- O projeto integração é realizado para o meio interno, onde os colaboradores têm a oportunidade de adquirir novos conhecimentos promovendo eventos e palestras que abordam interessem em comum.

- A Caminhada em Combate à hipertensão é destinada para a sociedade em geral, tanto para o meio interno quanto ao meio externo, proporciona um momento de recreação, lazer e saúde, a empresa ainda disponibiliza profissionais qualificados para a prática de aferição de pressão, orientação com professores de educação física e dicas de saúde.

- O projeto Flauta Cidadã é destinado a alunos da rede pública de ensino, realizado em parceria com a Câmara Municipal de Tangará da Serra, Secretaria Municipal de Educação e Cultura de Tangará da Serra, Secretaria Estadual de Cultura do Mato Grosso, Espaço Villa Lobos e Escola Estadual Jada Torres, tem o intuito de interagir as crianças através de uma atividade musical saudável, educando-as para conviverem em harmonia e se tornarem cidadãos de bem.

- O projeto $1^{\circ}$ passo - Manicure e Pedicure é destinado às mães dos alunos que participam do projeto flauta cidadã e alunos da escola Jada Torres, é desenvolvido em parceria com o Grupo Canopus e Escola Jada Torres e tem o objetivo de capacitar profissionalmente essas mães, elas ainda recebem palestras sobre empreendedorismo, higiene e saúde, em encontros semanais.

A Agro Amazônia Sistemas Mecanizados Ltda não realiza nenhum projeto voltado para a comunidade externa, porém investe na minimização da degradação do meio ambiente por ações provenientes do seu processo produtivo.

\subsection{Apresentação valores monetários contidos nos balanços.}

A tabela 1 apresenta as empresas que participam da premiação e são condecoradas com o Certificado de Responsabilidade Social de Mato Grosso. 
Tabela 1 - Demonstrativo das Empresas e seus principais indicadores em 2010.

\begin{tabular}{|c|c|c|c|c|c|c|}
\hline $\begin{array}{ll}\text { Organiz } & \text { Valores } \\
\text { ação } & \text { em Mil } \\
& \text { Reais }\end{array}$ & Rec. Liquida & $\begin{array}{c}\text { Corpo } \\
\text { Funcional }\end{array}$ & $\begin{array}{c}\text { Folha de } \\
\text { pagto Bruta }\end{array}$ & $\begin{array}{l}\text { Ambiente } \\
\text { Interno }\end{array}$ & $\begin{array}{l}\text { Comuni- } \\
\text { dade }\end{array}$ & $\begin{array}{c}\text { Meio } \\
\text { Ambiente }\end{array}$ \\
\hline $\begin{array}{l}\text { Agro Amazônia } \\
\text { Sistemas } \\
\text { Mecanizados } \\
\text { Itda. }\end{array}$ & 133.006 .000 & 193 & 4.878 .000 & 2.196 .000 & 0 & 89.000 \\
\hline Data Med Ltda. & 4.789.511,81 & 31 & $713.581,09$ & $57.229,00$ & $9.622,09$ & 0 \\
\hline $\begin{array}{l}\text { Inasb Planos } \\
\text { Odontológicos } \\
\text { Ltda. }\end{array}$ & $251.673,88$ & 4 & $108.061,77$ & $8.649,20$ & 2.786 .17 & 0 \\
\hline $\begin{array}{l}\text { Inviolável } \\
\text { Tangará Ltda. }\end{array}$ & $1.092 .154,94$ & 30 & $589.794,84$ & $13.210,06$ & $3.910,90$ & NC* \\
\hline $\begin{array}{l}\text { Minerva } \\
\text { Processamentos } \\
\text { de Dados } \\
\text { Contábeis Ltda. }\end{array}$ & $391.543,63$ & 18 & $253.954,16$ & $18.208,90$ & $5.868,54$ & NC* \\
\hline $\begin{array}{l}\text { Unimed Vale do } \\
\text { Sepotuba }\end{array}$ & $31.706 .451,39$ & 49 & $1.132 .205,25$ & $376.744,63$ & $15.216,75$ & 443.941,39 \\
\hline TOTAIS: & $171.237 .335,65$ & 325 & $7.675 .597,11$ & $2.670 .041,79$ & $34.618,28$ & $532.941,39$ \\
\hline
\end{tabular}

* NC: O modelo de Balanço Social utilizado pela empresa não disponibiliza item para identificar investimento ao meio ambiente.

Fonte: Dados da pesquisa.

Como se pode ver na tabela 1 , os recursos são direcionados substancialmente ao meio interno, em um total de $\mathrm{R} \$ 3.237 .601 .46$, foi direcionado aos funcionários $\mathrm{R} \$ 2.670 .041,79$ o que equivale a $82,47 \%$ do total, ao meio externo (comunidade) $\mathrm{R} \$ 34.618,28$ o que representa $1,07 \%$ e finalizando, para o meio ambiente foi destinado o valor de $\mathrm{R} \$ 532.941,39$, o que representa $16,46 \%$ do total. 


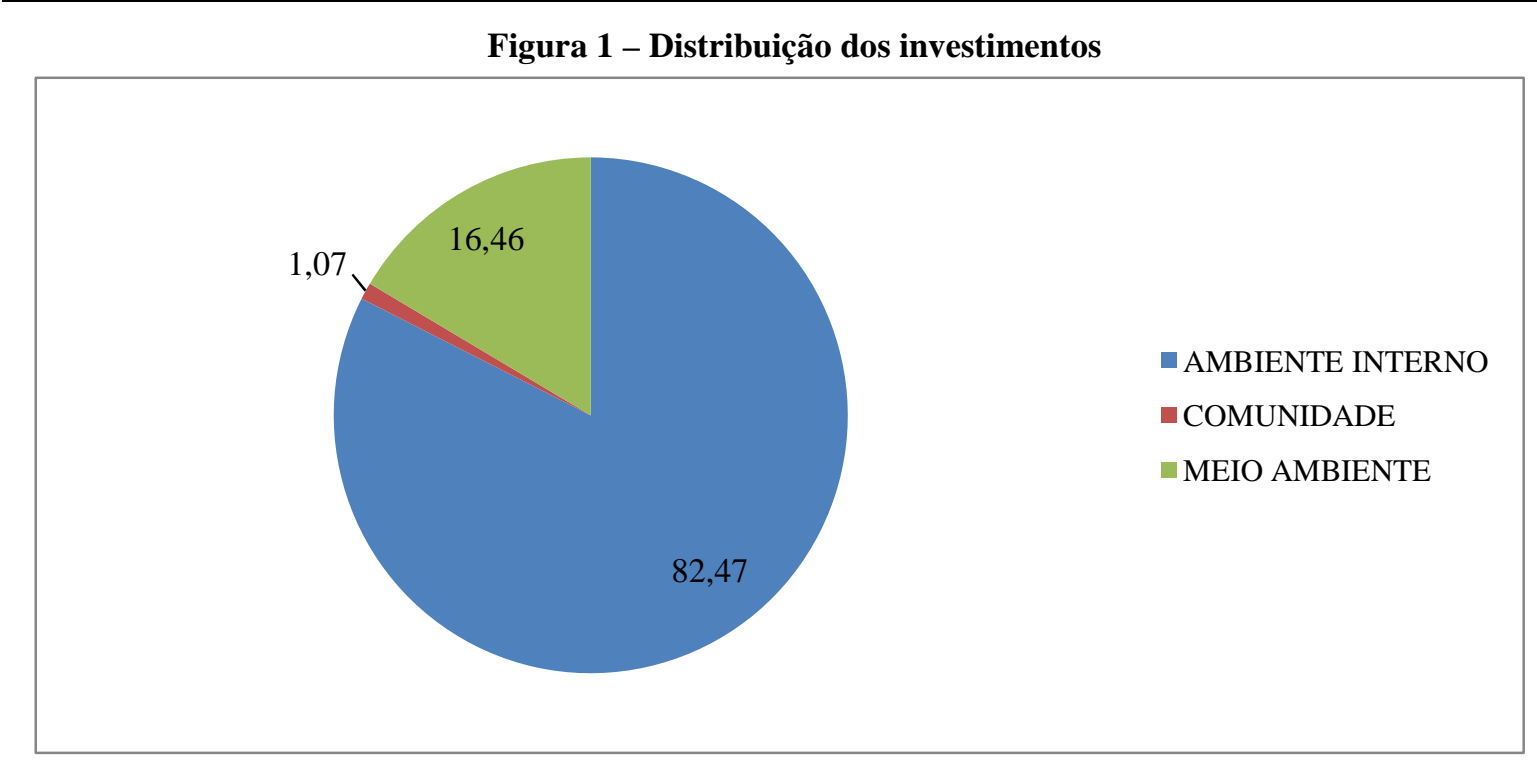

Fonte: Dados da pesquisa

Como representado no gráfico à cima, pode-se ter a percepção que as empresas preferem investir no meio interno (colaboradores), o que demonstra o interesse das organizações em investir onde o retorno é mais certo, tendo em vista que funcionários bem assistidos produzem mais e com melhor qualidade. As empresas que têm seus balanços aqui analisados como se pode averiguar na tabela 1 , são empresas de pequeno porte, com exceção da Agro Amazônia que possui um corpo funcional de 193 funcionários no ano de 2010.

O fato de empresas investirem preferencialmente no corpo funcional está diretamente ligado ao interesse voltado para o crescimento da entidade, segundo Medrado 2008, a satisfação e motivação das pessoas nela inserida é determinante para seu bom desempenho.

\subsection{Do questionário aplicado}

Com o objetivo de discutir e analisar o entendimento das empresas que ainda não publicam seus balanços, foi aplicado questionário com perguntas destinadas a atingir este objetivo, ainda no momento do recolhimento dos mesmos foi discutido sobre o assunto com o responsável pelo preenchimento.

As empresas que foram entrevistadas fazem parte do mesmo segmento de mercado das empresas detentoras do certificado de responsabilidade social de MT, de acordo com o resultado da pesquisa, $60 \%$ dessas empresas possuem em seu quadro funcional de 1 a 5 colaboradores, o que as enquadra como micro empresas. Conforme figura 2, com uma representação de $20 \%$ parece às empresas que possuem de 6 a 10 funcionários, $15 \%$ têm de 11 a 20 funcionários e apenas $5 \%$ contam com um corpo funcional de 21 a 50 funcionários. 
Análise da responsabilidade social das empresas de Tangará da Serra através do Balanço Social

Kátia Regina Endringer

Maykon J. Barbieri Camargo

Figura 2 - Quadro funcional das empresas entrevistadas

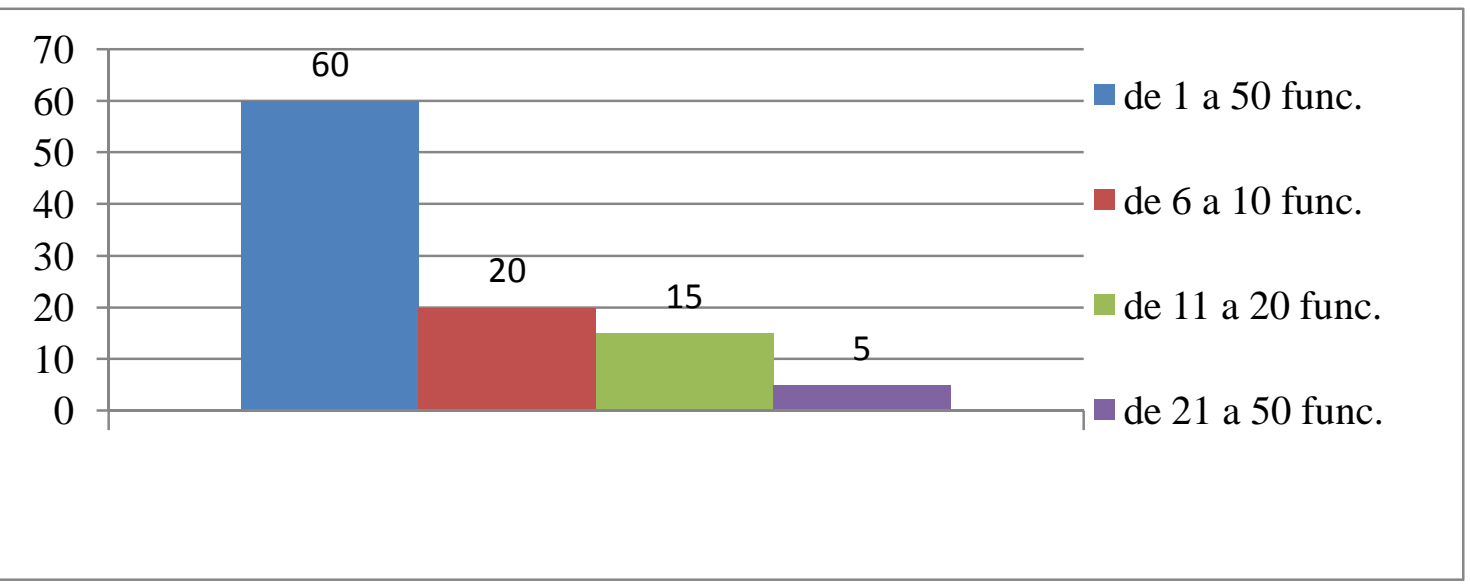

Fonte: Dados da pesquisa

Ainda foi questionado se as empresas fornecem algum tipo de beneficio a esses funcionários, e conforme resultado apurado foi constatado que $62,5 \%$ do total de 40 empresas questionadas não oferecem nenhum tipo de benefícios aos colabores e 37,5\% delas oferecem aleatoriamente plano de saúde, plano funeral, plano odontológico, vale alimentação.

Figura 3 - Distribuição entre empresas que fornecem ou não benefícios.

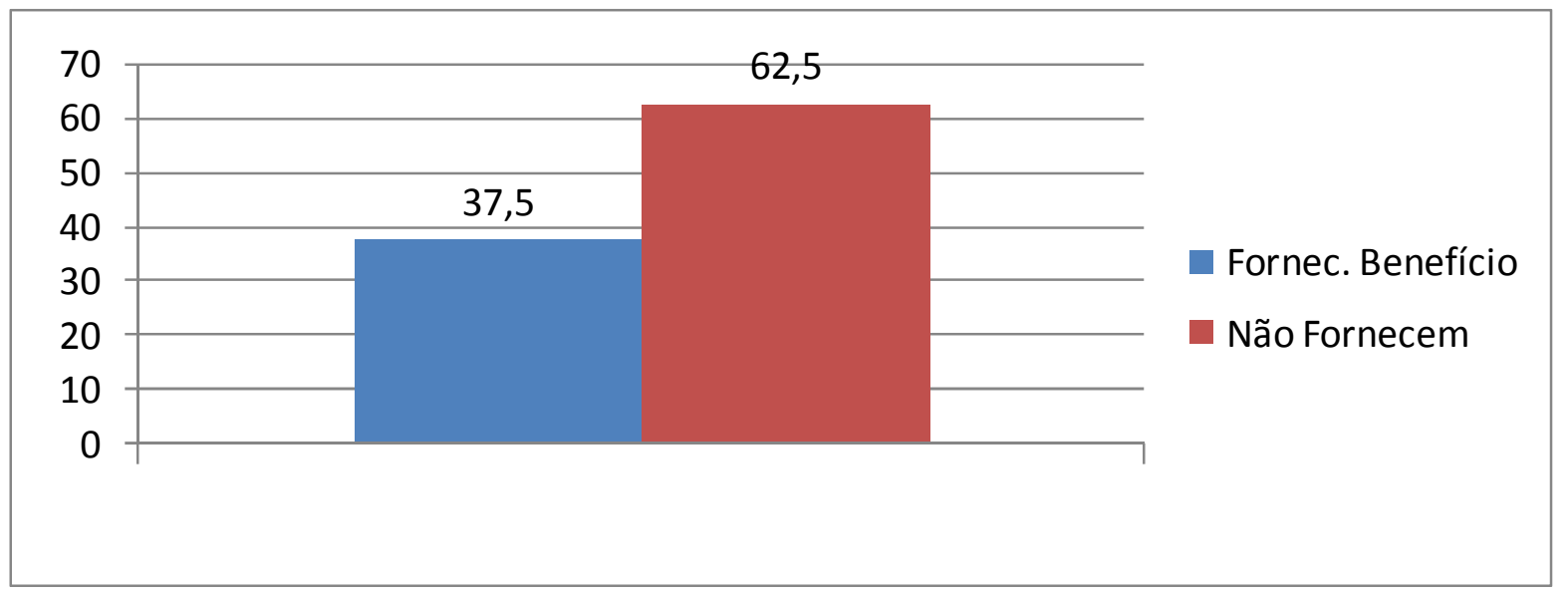

Fonte: Dados da pesquisa

Quanto ao meio externo (comunidade), foi questionado se as empresas desenvolvem algum projeto destinado a ele, e fazendo relação às empresas que publicam seus balanços, os recursos destinados a comunidade são mínimos, sendo que de 40 empresas questionadas apenas uma realiza atividade voltada à sociedade, uma representação de $2,5 \%$.

Para o meio ambiente, várias empresas se demonstraram interessadas em sua conservação, dentre as empresas questionadas 12 se identificaram como zeladoras e conservadoras. Dentre as ações foram identificadas coleta seletiva do lixo, distribuição de mudas no dia da arvore, limpeza de córrego de uma propriedade próxima a cidade, 
Análise da responsabilidade social das empresas de Tangará da Serra através do Balanço Social

reutilização de papel (rascunho), descarte adequado de óleo. Para realizar essas ações não é necessário despendimento de recursos monetários, apenas o bom senso e colaboração de todos são suficientes para desenvolvê-las.

Pode-se então com base nessas informações, entender que as empresas preferem destinar seus recursos para o meio interno (funcionários) onde o retorno em forma de satisfação e aumento da produtividade são mais perceptíveis e eficientes para a entidade. Ainda colaborar com a preservação do meio ambiente, o que não exige muito investimento de dinheiro ou tempo, apenas uma reeducação e conscientização das pessoas inseridas no processo produtivo da empresa.

Foi exposta a idéia de empresa socialmente responsável as empresas questionadas, e sobre sua visão a respeito da importância do investimento nos meios interno e externo e meio ambiente, as empresas se mostraram divididas na opinião. Acharam essencial investir para criar ou manter uma boa imagem perante a sociedade $45 \%$ das empresas, $40 \%$ julga apenas relevante e $15 \%$ responderam que tanto faz.

Figura 4 - Opinião das empresas sobre a publicação do balanço social.

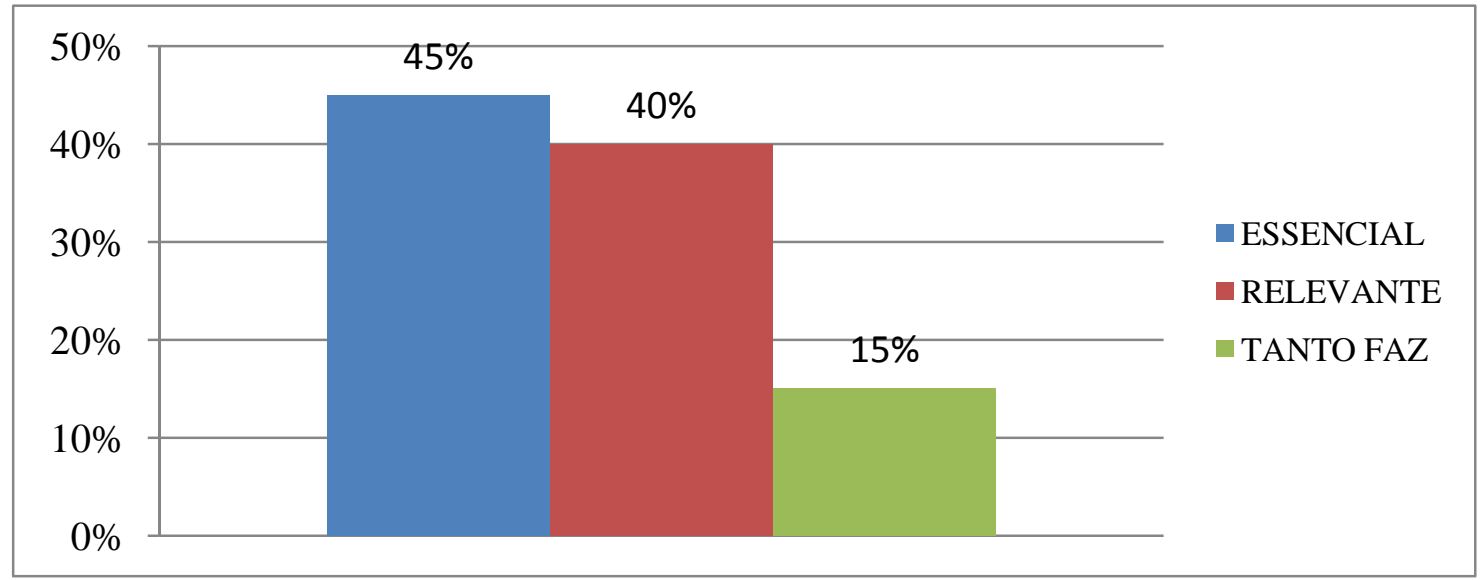

Fonte: Dados da pesquisa

Pode-se entender que, $15 \%$ é um percentual pequeno de empresas que julgam desimportante o comportamento socialmente responsável, tendo em vista que apenas 37,5\% das empresas entrevistadas investem nas pessoas envolvidas direta e indiretamente no seu processo de produção e no meio ambiente, chega-se a conclusão que algumas empresas deixam de investir por falta de recursos.

Quando questionadas sobre o motivo da falta de interesse em confeccionar seus balanços e dar publicidade a eles, as empresas que não oferecem nenhum tipo de beneficio 
Análise da responsabilidade social das empresas de Tangará da Serra através do Balanço Social

Kátia Regina Endringer

Maykon J. Barbieri Camargo

$(62,5 \%)$ responderam que não o fazem por não ter o que demonstrar no balanço. $\mathrm{E}$ as empresas que oferecem algum benefício $(37,5 \%)$ responderam que nunca cogitaram a hipótese de fazê-lo.

Figura 5 - Opinião das empresas acerca do porque não publicar seus balanços

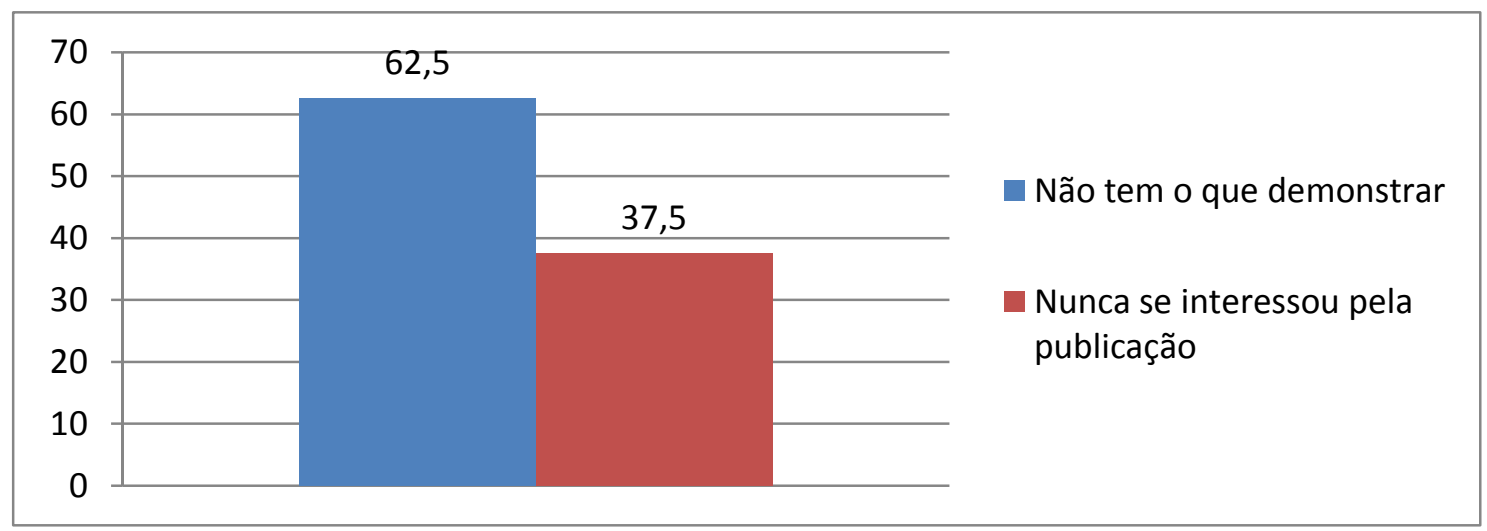

Fonte: Dados da pesquisa

As empresas que publicam seus balanços foram questionadas sobre o motivo que as faz praticar esta ação, e 100\% delas responderam que julgam importante investir em ações que beneficiem a sociedade e meio ambiente e além desse motivo 50\% dessas empresas ainda têm o entendimento que a divulgação desses atos incentiva outras empresas a fazê-lo.

\section{CONSIDERAÇÕES FINAIS}

Como apresentado neste trabalho, o tema responsabilidade social no Brasil desde a década de 60 vem se tornando cada vez mais comum e discutido em várias esferas da sociedade, e nos dias atuais com a crescente cobrança por comportamento socialmente responsável das empresas, estas, cada vez mais procuram se adequar a nova mentalidade.

Em Tangará da Serra conforme discorrido, apenas algumas empresas publicam seus balanços, a conclusão que se pode chegar ao final desta pesquisa é que, as empresas realmente estão conscientes sobre a necessidade de investir nos colaboradores, comunidade e ainda em preservar o meio ambiente. Porém, apenas algumas empresas já conseguem reservar parte do seu lucro para esse fim, enquanto grande maioria ainda trabalha direcionada ao aumento do patrimônio para conseguir se manter competitiva no mercado.

Com base nos objetivos gerais e específicos, trabalhou-se para obter as respostas referentes a eles, sendo assim os mesmo foram atingidos, tendo em vista que se tinha como objetivo identificar os benefícios oferecidos aos meios (interno e externo) das 
Análise da responsabilidade social das empresas de Tangará da Serra através do Balanço Social

Kátia Regina Endringer

Maykon J. Barbieri Camargo

empresas que publicam seus balanços em Tangará da Serra e constatou-se que estes benefícios são os mais variados possíveis, pois existem recursos direcionados internamente, para colaboradores, recursos aplicados no meio ambiente e recursos despendidos para a sociedade.

Referente ao interesse das empresas no tema responsabilidade social a maioria das empresas responderam que julga importante, tanto para a boa imagem da empresa, quanto para incentivar outras empresas em praticar ações para este fim. Logo se pode concluir que as empresas estão interessadas no tema, pois na visão das mesmas se comportar de maneira socialmente responsável traz benefícios para a entidade.

Quanto ao problema dessa pesquisa, conclui-se que os aspectos das empresas detentoras do Certificado de Responsabilidade são de empresas que já conquistaram seus objetivos financeiros e hoje trabalham no intuito de manter sua competitividade através de um diferencial que as valorize ainda mais, que é o comportamento responsável diante das causas sociais. E quanto às empresas que ainda não dedicam investimento a essas causas, pode-se concluir que estas ainda trabalham no intuito de gerar recursos e agregar valor monetário ao seu patrimônio, porém a maioria destas já está consciente quanto à necessidade da prática de um comportamento responsável com os meios em que ela se encontra inserida.

\section{REFERÊNCIAS}

AMOROSO, S. Responsabilidade social: menos marketing e mais ações. Jornal valor. Agosto 2003.

ASHLEY, P. A.; COUTINHO, R. B. G.; TOMEI, P. A. Responsabilidade social corporativa e cidadania empresarial: uma analise conceitual comparativa 1. Enanpad, Set/2000.

ASSOCIAÇÃO DOS DIRIGENTES CRISTÃOS DE EMPRESA DE SÃO PAULO (ADCESP) Disponível em:< http://www.adcesp.org.br/ >acesso em: Out /2011.

BAGGENSTOSS, S. A difusão da responsabilidade social: enfoque no certificado de responsabilidade social de Mato Grosso. 2009. 98f. Dissertação - (Mestrado) Universidade Federal de São Carlos, 2009.

BALDO, R. A empresa cidadã frente ao balanço social. XXV Congresso Brasileiro de Ciências da Comunicação. Setembro 2002.

FREY, M. R.; FILHO, U. S. Análise das ações sociais das empresas detentoras do selo IBASE/Betinho - 2000. Contabilidade Vista e Revista, v. 14, n. 2, p. 9-28, agosto 2003.

FUZZI, L. P. Metodologia da pesquisa de campo: O que é a pesquisa de campo?. 29 de março de 2010. Disponível em:<http://profludfuzzimetodologia.blogspot.com> acesso em: 08/11/11.

IBASE, Instituto Brasileiro de Análises Sociais e Econômicas. Quem somos. Disponível em:<http://www.ibase.br/pt/quem-somos> acesso em: 10/out/2011. 
Análise da responsabilidade social das empresas de Tangará da Serra através do Balanço Social Kátia Regina Endringer

Maykon J. Barbieri Camargo

INSTITUTO ETHOS. Empresas e responsabilidade social. Conferência internacional 2005. Disponível em: <www.ethos.org.br> acesso em: 12/10/11.

KREITLON, M. P. A ética nas relações entre empresas e sociedade: Fundamentos teóricos da responsabilidade social. XVII Enanpad. Curitiba, 2004.

MARTINS, C. M. F.; BERNARDO, D, C, R.; MADEIRA, G, J. Origem e evolução social no Brasil. Contab. Vista e Revista, v.12, n.1, p.105-116, Abril 2002.

MATO GROSSO ASSEMBLÉIA LEGISLATIVA DO ESTADO. Lei 7.687, de 25 de junho de 2002. Cria o certificado de responsabilidade social no estado de Mato Grosso e dá outras providencias. Disponível em:< http://www.al.mt.gov.br > Acesso em: 10/out/2011.

MEDRADO, V. Empresas investem em motivação de colaboradores. 14 de agosto de 2008. Disponível em: $<$ http://farolcomunitario.blogspot.com.br/2008/08/empresas-investem-emmotivao-de.html > acesso em: 08/04/12.

NEGRA, C.A.S; TEIXEIRA, F,S; CARMO, R.F. O balanço social na gestão das instituições de ensino superior. Contabilidade vista e revista, v.12, n.3, p. 9-34. Dez/2001.

NETO MELO, F. P.; FROES, C. Responsabilidade social e cidadania empresarial A administração do terceiro setor. Rio de Janeiro: Qualitymark 2002.

OLIVEIRA, J. A. Responsabilidade social da empresa. Revista Adm. Empr. v.2,4 n.4, p 203-210, out/dez 1984.

OLIVEIRA, R. M. et al. Relação entre investimento social corporativo e o valor das empresas Brasileiras. Repec, v. 4, n.2, p. 62-80, 2010.

QUINTANA, A.C. et Al. Balanço social: a resposta as novas exigências sociais. Revista acadêmica de economia. Disponível em:<

http://www.eumed.net/cursecon/ecolat/br/07/acq.htm> acesso em:07/08/11.

RAUPP, Fabiano Maury; BEUREN, Ilse Maria. Metodologia da pesquisa aplicável às ciências sociais. Como elaborar trabalhos monográficos em contabilidade. 3.ed. São Paulo: Atlas, 2006.

SAMPIERI, R. H.; COLLADO, C. F.; LUCIO, P. B. Metodologia de pesquisa. 3 ed. São Paulo, Mcgraw-Hill, 2006, p. 2-20.

SANTOLIN, A.D.; FREY, M. R. O papel do balanço social na gestão empresarial. Contab. Vista e Revista, v.16,n.2, p 61-81. Belo Horizonte, Agosto 2005.

SANTOS, E. C. R. M. Responsabilidade social ou filantropia? Sanare. Revista Técnica da Sanepar. Curitiba, v.20, n.20, p. 18-27, jul./dez. 2003.

SILVA, C. A. T.; FREIRE, F. S.. Balanço Social Teoria e prática. São Paulo: Atlas 2001.

TINOCO, J. E. P.. Balanço social, Uma abordagem da transparência e da responsabilidade pública das organizações. São Paulo: Atlas 2001.

URSINI, T. S. SEKIGUCHI, S. Desenvolvimento sustentável e responsabilidade social. Rumo a terceira geração e normas ISO. Instituto Uniemp. São Paulo, 2005.

VARELLA, P. S.; COSTA, R. R.; DOLABELLA, M. M.; Balanço social: demonstrativo da função social da empresa. Contabilidade vista e revista. v. 10, n. 2, p. 28-35. Belo Horizonte, Set. 1999. 
Análise da responsabilidade social das empresas de Tangará da Serra através do Balanço Social Kátia Regina Endringer

Maykon J. Barbieri Camargo

VEIGA-NETO, A. R.; PANHOSSI, K. L.; GODOY, A. F. M. Responsabilidade social em empresas privadas e sua relação com o terceiro setor. REAd - Edição 39 v.10 n.3, mai/jun 2004. 